\title{
Temperature and Frequency Effects in a High-Performance Superconducting Bearing*
}

\author{
Arthur C. Day, ${ }^{1}$ John R. Hull, ${ }^{2}$ Michael Strasik, ${ }^{1}$ Phil E. Johnson, ${ }^{1}$ \\ Kevin E. McCrary, ${ }^{1}$ John Edwards, ${ }^{1}$ John Mittleider, ${ }^{1}$ \\ James R. Schindler, ${ }^{1}$ Richard A. Hawkins, ${ }^{1}$ and Michael Yoder ${ }^{1}$ \\ ${ }^{1}$ Boeing Phantom Works \\ Seattle, WA 98124 \\ ${ }^{2}$ Energy Technology Division \\ Argonne National Laboratory \\ Argonne, IL 60439
}

August 2002

The submitted manuscript has been created by the
University of Chicago as Operator of Argonne National
Laboratory ("Argonne") under Contract No. W-31-109-ENG-
38 with the U.S. Department of Energy. The U.S.
Government retains for itself, and others acting on its behalf,
a paid-up, nonexclusive, irrevocable worldwide license in
said article to reproduce, prepare derivative works, distribute
copies to the public, and perform publicly and display
publicly, by or on behalf of the Government.

Presented at the 2002 Applied Superconductivity Conference, Houston, TX, August 4-9, 2002.

*The U.S. Department of Energy, Offices of Energy Efficiency and Renewable Energy, partially supported the work under Cooperative Agreement DE-FC36-99G010825, Contract W-31-109Eng-38, and Sandia National Laboratories Contract 24412. 


\title{
Temperature and Frequency Effects in a High-Performance Superconducting Bearing
}

\author{
Arthur C. Day, John R. Hull, Michael Strasik, Phil E. Johnson, Kevin E. McCrary, John Edwards, \\ John Mittleider, James R. Schindler, Richard A. Hawkins, and Michael Yoder
}

\begin{abstract}
A high-temperature superconducting (HTS) bearing was fabricated and tested by itself and as a component in a 1-kWh and a 10-kWh flywheel energy system (FES). The rotational losses of the HTS bearing as a function of rotational rate and HTS temperature were determined. The 1-kWh FES was tested with a motor/generator and with an eddy current clutch to determine the motor/generator losses.
\end{abstract}

Index Terms-superconducting bearing, flywheel energy storage, levitation

\section{INTRODUCTION}

$\mathrm{T}$ HE availability of high-temperature superconducting (HTS) bearings enables the possibility of attaining very low idling losses in a flywheel energy system (FES) [1]. The use of the HTS bearing in a FES is often suggested as one of the first applications of melt-textured bulk HTSs, and several laboratory prototypes of this FES concept have been tested [2]-[6]. Quantification of the bearing losses and optimization of the FES system with respect to the HTS temperature are important factors in the design. Minimization of other system losses, especially those when the flywheel is idling at high speed, is also important for commercial success of the FES.

In this paper, we report rotational loss as a function of temperature and speed of an HTS bearing designed for a 10$\mathrm{kWh}$ FES. The rotating component consists of three rings of radially-polarized permanent magnets separated by highpermeability pole pieces. The stator is an array of melttextured $\mathrm{Y}-\mathrm{Ba}-\mathrm{Cu}-\mathrm{O}$ that is cooled by a thermosyphon loop of liquid nitrogen that is cooled by a closed-cycle refrigeration system. Tests were conducted on the bearing itself at speeds up of to $15,000 \mathrm{rpm}$. Tests were also conducted to 12,000 rpm with the bearing mounted on a $1-\mathrm{kWh}$ rotor and are in progress with a 10-kWh rotor.

Manuscript received August 4, 2002. The U.S. Department of Energy, Offices of Energy Efficiency and Renewable Energy, partially supported the work under Cooperative Agreement DE-FC36-99G010825, Contract W31-109-Eng-38, and Sandia National Laboratories Contract 24412.

A. C. Day is with the Boeing Phantom Works, Seattle, WA 98124 USA (telephone: 425-234-2669, e-mail: arthur.c.day@boeing.com).

M. Strasik, P. Johnson, K. McCrary, J. Edwards, J. Mittleider, J. Schindler, R. Hawkins, and M. Yoder are with the Boeing Phantom Works, Seattle, WA 98124 USA.

J. Hull is with Argonne National Laboratory, Argonne, IL 60439 USA (telephone: 630-252-8580, e-mail: and jhull@anl.gov).

\section{DESIGN}

The FES system studied here consists of several major subassemblies that include a rim, hub, lift magnets, stability magnet, HTS, cooling, power I/O, vacuum system, containment, and instrumentation. The HTS bearing consists of the stability magnet and the HTS array. Each subassembly is described below. Some elements of the FES design have been described previously [7], [8].

\section{A. HTS Bearing}

A bearing for the $1-\mathrm{kWh}$ and $10-\mathrm{kWh}$ flywheel systems has been built and characterized. The rotating component, shown in Fig. 1, consists of three rings of radially polarized permanent magnets separated by ferromagnetic steel pole pieces. The steel rings both 'turn' the flux outwards so that it will have a high gradient within the adjacent superconductor, and serve as support surfaces for the mechanically weak permanent magnets. The magnet support structure includes a fiber-reinforced hoop on the outer diameter of the magnet assembly, and a fiberglass laminate hub structure to transfer loads between the magnets and a central shaft. At the center of the assembly is shown a touch-down bearing that is used to hold the rotor when the HTSs are warm and to help confine any positional excursions when it is rotating. The assembly is normally oriented facedown and positioned several $\mathrm{mm}$ above a LN-cooled cryostat containing YBCO crystals. The bearing stiffness was optimized by using finite-element modeling to maximize the field gradients within the crystals.

Each permanent magnet ring consists of an assembly of arc segments. The magnets are segmented to reduce the tendency to fracture under centrifugal loading. Each arc segment is magnetized uniformly in the horizontal direction, with the direction of magnetization corresponding to the middle radius of the arc. Thus, there is a discontinuity of magnetization at the boundary between segments. The discontinuity is mitigated somewhat by the pole pieces. Nevertheless, there is a measurable circumferential inhomogeneity of the magnetic field that is associated with the segment gaps. The mass $m$ of the bearing test rotor is $9 \mathrm{~kg}$ and its moment of inertia $I_{p}$ is $0.061 \mathrm{~kg}-\mathrm{m}^{2}$.

The crystal array for this bearing is affixed to the underside of the cryostat lid as shown in Fig. 2. Each crystal is a melttextured single-domain YBCO pellet. The YBCO tiles are typically hexagons with a tip-to-tip dimension of $36 \mathrm{~mm}$ and 


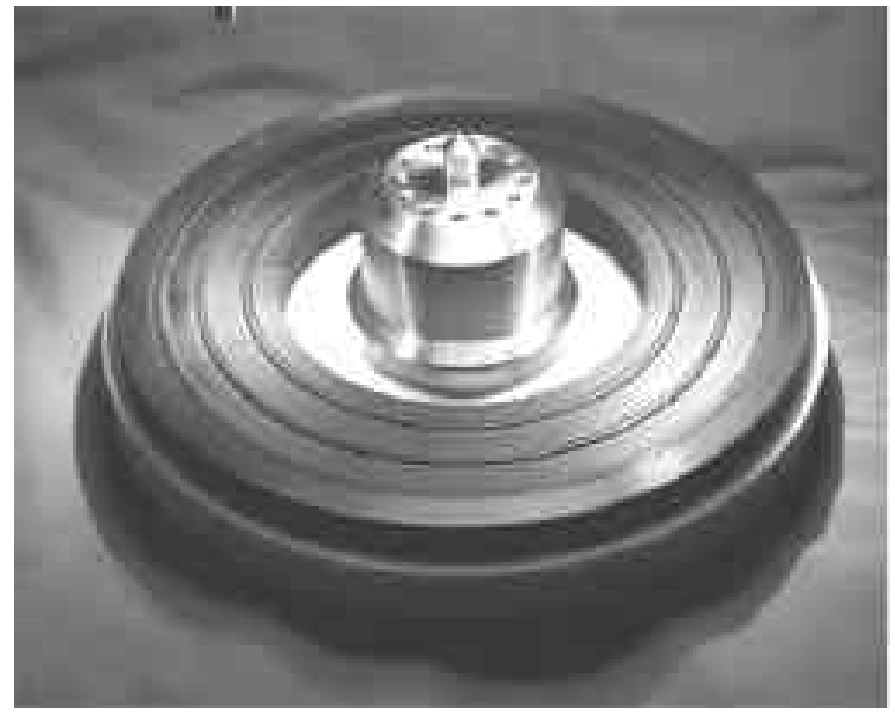

Fig. 1. Magnet assembly for an HTS bearing, shown here installed on a bearing test rotor.

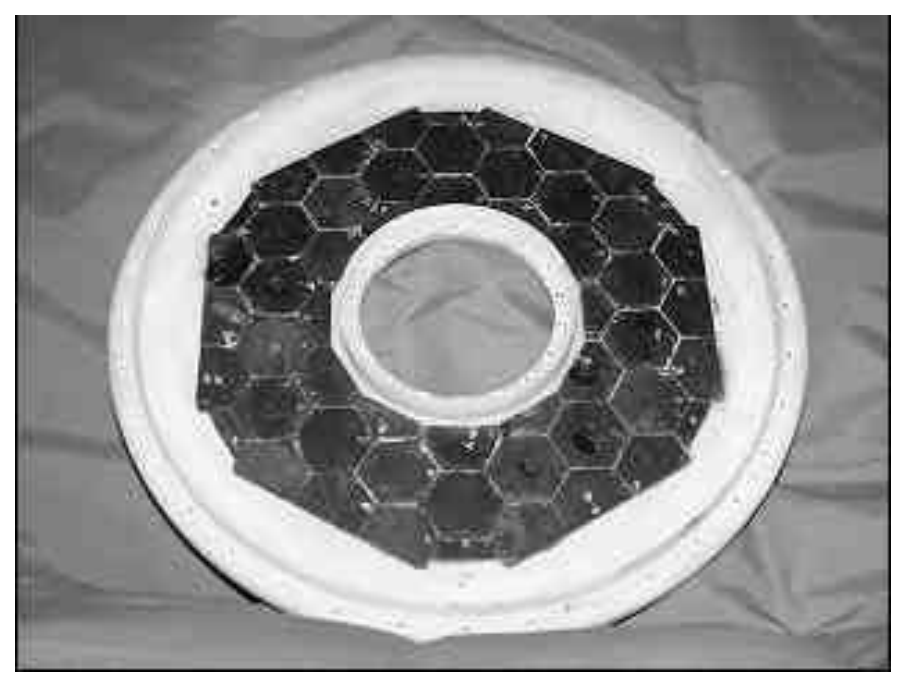

Fig. 2. YBCO crystal array on underside of cryostat lid.

a thickness of $4.5 \mathrm{~mm}$. The HTS array is housed in a G-10 cryostat and bathed in pool-boiling liquid nitrogen. When this paper refers to working gaps for the bearing it does not include the several $\mathrm{mm}$ thickness of the cryostat lid. We are able to cool the crystals with gravity-fed nitrogen at $77 \mathrm{~K}$ or with a closed-loop refrigeration system at temperatures as low as $65 \mathrm{~K}$.

\section{B. 1-kWh Rotor}

A relatively simple and low-cost rotor was constructed to demonstrate the ability of an HTS bearing to suspend and spin a significant mass of $45 \mathrm{~kg}$, including the magnets and hub. The basic construction of this rotor is shown in Fig. 3. The splined hub design was due originally to Toray Composites and was modified by Boeing to reduce mass.

The rotor size made it possible to accelerate and decelerate it with an eddy-current clutch and a 3-kW motor/generator,

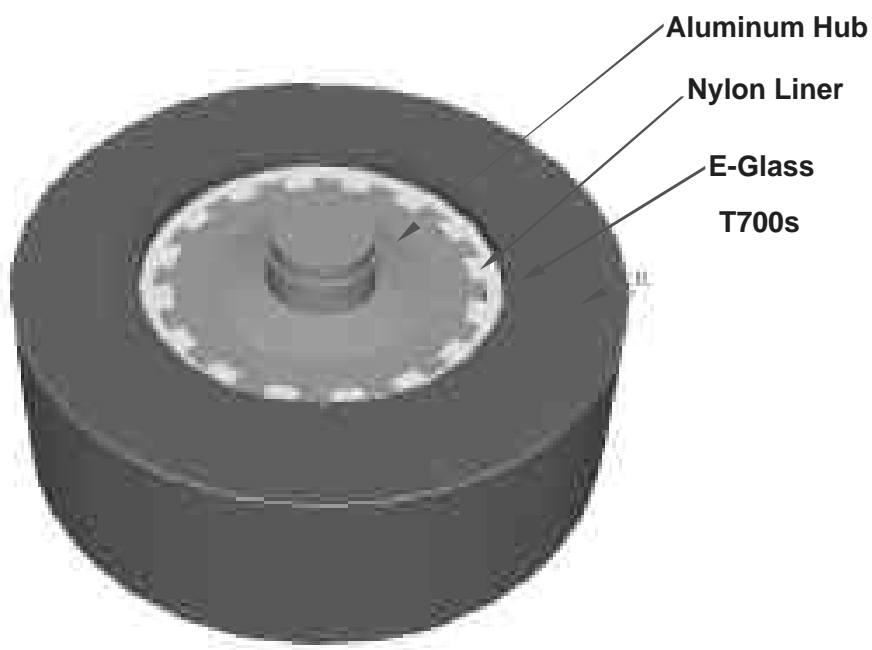

Fig. 3. 1-kWh rotor with Toray/Boeing G-S hub design.

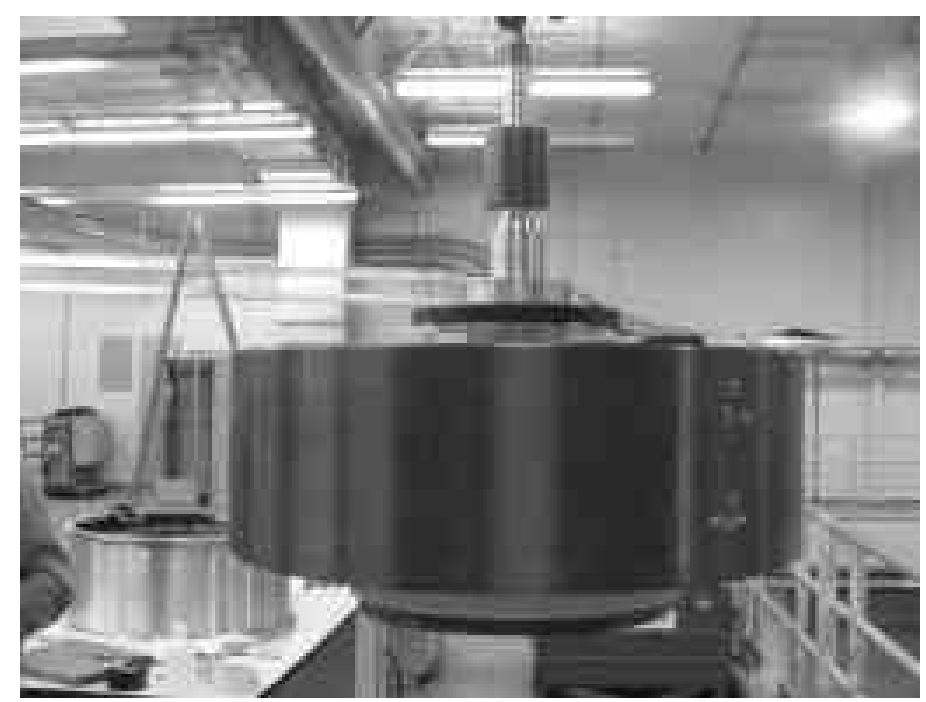

Fig. 4. Completed 1-kWh flywheel. Lift magnet and motor rotor are above the rim; magnet assembly for HTS bearing is below.

thus making it possible to measure the motor idling losses. Early in 2001, the eddy-current clutch was used to spin the rotor to speeds up to $8,000 \mathrm{rpm}$. In February of 2002, modifications were made to this rotor to adapt a $3-\mathrm{kW}$ Ashman Technologies motor/generator to the shaft. The complete flywheel is shown in Fig. 4. The motor/generator and a lift magnet ring are above the rim while the main magnet assembly is located below. At the rim's rated speed of 24,000 rpm this wheel would yield a stored energy of approximately $1 \mathrm{kWh}$ while maintaining a factor of safety of 2.

Most of the rotor's levitation is provided by a separate permanent magnet lift bearing that consists of one stator ring and one rotor ring. Compared with all-HTS designs, this approach reduces the magnetization of the HTS, which may contribute to improved loss characteristics. It also requires less HTS material since only surface currents are required for stability. 


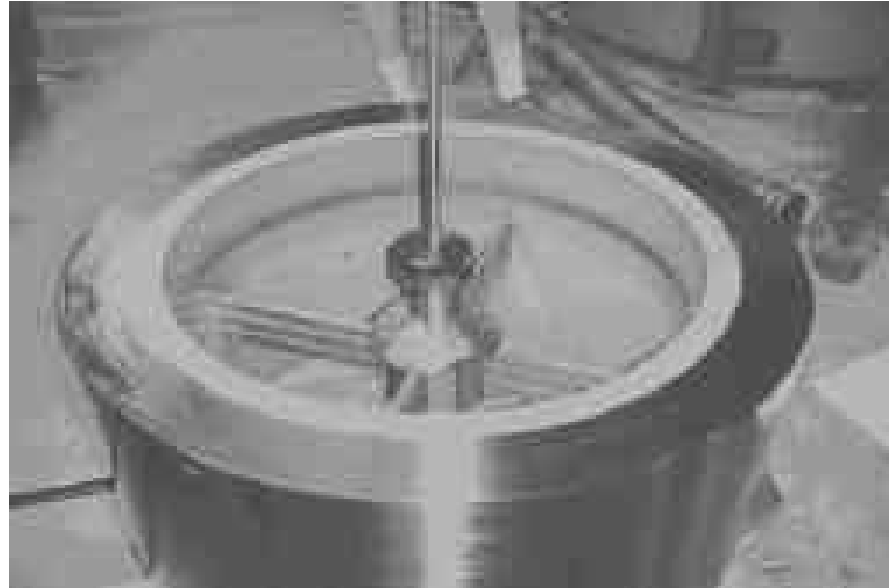

Fig. 5. Rotor for a 10-kWh flywheel after quill test at 14,000 rpm.

\section{10-kWh Rotor}

In a parallel effort we have been designing and testing components for a flywheel that will store $10 \mathrm{kWh}$ at 20,000 $\mathrm{rpm}$. The main structure of the wheel is shown in Fig. 5 after spin testing on a quill. The HTS bearing and $3-\mathrm{kW}$ motor/generator is of identical design to those used in the 1$\mathrm{kWh}$ flywheel. The complete flywheel including magnets and motor has a mass of $177 \mathrm{~kg}$. It uses a near-zero-stiffness lift bearing consisting of two stator rings and one rotor ring of permanent magnets. As of July 2002 this flywheel has been levitated and spun to a few hundred rpm.

\section{Power Input and Output}

Two methods were used to take energy in and out of the flywheel. The first is an eddy current clutch, adapted from [4]. In this method a set of permanent magnets are embedded at a fixed radius in a high-strength aluminum disk to form the clutch and is connected to an external motor. When engaged, the rotating clutch is located approximately $1 \mathrm{~cm}$ above an aluminum plate that is attached to the rotor. Any difference in rotational speed between the clutch and the plate induces eddy currents in the plate and creates rotational drag between the clutch and the plate. If the clutch spins faster than the plate, the flywheel rotation accelerates. If the clutch spins slower than the plate, the flywheel decelerates. The clutch can be disengaged by moving it vertically away from the plate so that the only drag terms acting on the flywheel are from the rotating magnets and windage.

The second method to add or remove energy to the flywheel is with a motor/generator. In this case a set of radially polarized permanent magnets is attached to the shaft of the flywheel at the top. The rotor magnets interact with a stator that is composed of copper wound coils attached to a toothless ferromagnetic backiron. The stator coils are physically supported from the top of the vacuum chamber.

\section{E. Balance of System}

The flywheel systems were tested in a vacuum chamber. This was typically pumped down with a turbo-molecular pump to a pressure of $6 \times 10^{-5}$ torr but was sometimes held at higher pressures to measure the influence of windage. The low temperature of the cryostat assisted in attaining a good vacuum. Sensors were provided for YBCO tile temperature and also for rotor horizontal and vertical positions and vibrations. Position and vibration sensing were done with Keyence model 2400 laser position sensors, which have bandwidth settings of up to $50 \mathrm{kHz}$.

\section{BeARING PERFormance}

\section{A. Bearing Stiffness}

Bearing axial stiffness was measured by supporting the bearing rotor some small distance above the cryostat during cool-down of the HTS, waiting for full cooling of all crystals, then recording the distance of drop upon release. Both laser position sensors and small video cameras in the test chamber monitor the drops. The ratio of gravitational force to displacement then gives the axial stiffness. The vertical displacements were small but not negligible, typically of the order of $0.5 \mathrm{~mm}$. This condition is fairly close to that which occurs for the $1-\mathrm{kWh}$ and $10-\mathrm{kWh}$ flywheel, which use a separate set of permanent magnets for most of the system thrust load.

The lateral stiffness of the bearing was measured by observing the resonant frequency of the bearing rotor. This can be observed as the frequency at which a peak occurs in the Fourier decomposition of the vibrational amplitude and also as the rotational frequency at which the radial amplitude is largest. To first order the stiffness $K$ is derived from $K=$ $m \omega^{2}$, where $m$ is the rotor mass and $\omega$ is the angular frequency. There is a small correction based on gyroscopic stiffening, which we used to obtain the lateral stiffness reported below. An example of the horizontal vibration amplitudes in two perpendicular planes at various rotational speeds is shown in Fig. 6. In the figure, a large number of position points indicates the envelope of sensed position and includes effects a large runout component as well as vibration. The bearing resonance appears at about $350 \mathrm{rpm}$.

The static axial stiffnesses ranged from approximately 80-190 $\mathrm{N} / \mathrm{mm}$ as the working gap was varied from $5 \mathrm{~mm}$ to less than $2 \mathrm{~mm}$. With a nominal gap of $3.2 \mathrm{~mm}$ the axial stiffness was $144 \mathrm{~N} / \mathrm{mm}$. The lateral stiffness at the same gap, measured with the bearing resonance at $766 \mathrm{rpm}$, was determined to be $69 \mathrm{~N} / \mathrm{mm}$. Since the flywheel's motor/generator and the lift magnets have negative stiffnesses considerably less than this, the bearing should be able to support the flywheel as long as critical speeds can be avoided or damped out. It is also interesting that the ratio of axial to radial stiffness is very close to 2:1. This is in accord with recent theoretical descriptions of a superconducting analogue to Earnshaw's 


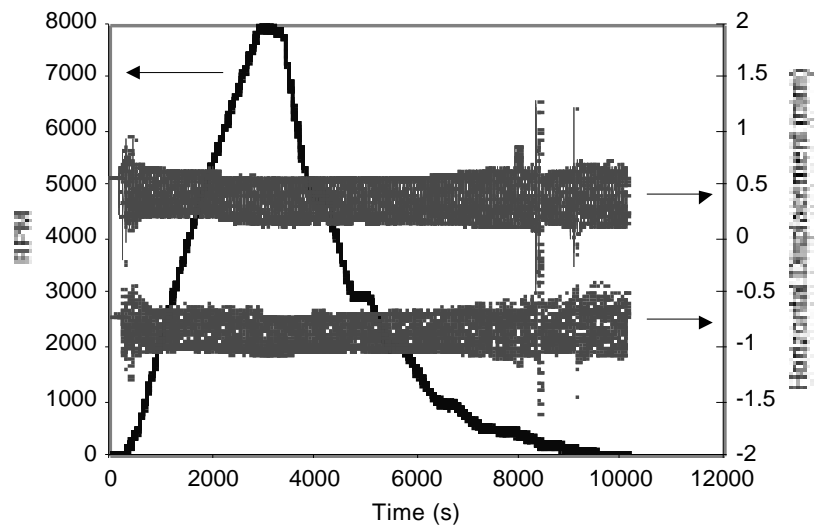

Fig. 6. Rotation speed and horizontal displacements for 1$\mathrm{kWh}$ rotor as function of time. The two horizontal displacements are perpendicular to each other.

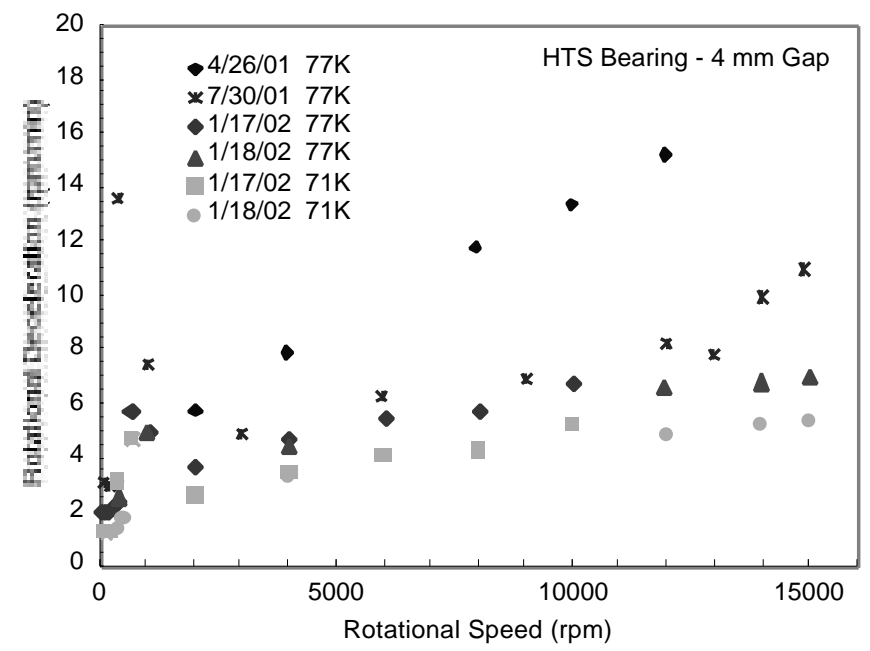

Fig. 7. Rotational losses as a function of speed for the HTS bearing at different HTS temperatures.

theorem [9]. To first order, the stiffness was independent of temperature with a slight increase in stiffness as temperature decreased.

\section{B. Bearing Losses}

Several sets of data of the rotational deceleration rate at different speeds for the HTS bearing with the eddy current clutch disengaged are shown in Fig. 7. The 4/26/01 and 7/30/01 data were taken with the HTS array cooled by flowing liquid nitrogen that was gravity fed to the cryostat at a pressure of $\sim 3 \mathrm{kPa}(\sim 0.5 \mathrm{psi})$ above ambient. The other four sets were taken with the HTSs cooled by flowing liquid nitrogen in a thermosyphon loop that contained the cold head of a cryocooler and the upper end of the loop and the HTSs at the lower end.

The bearing power loss $P$ in watts can be determined from the deceleration rate $D$ in rpm/minute by the formula $P=D I_{p}$ $S 4 \pi^{2} / 60^{3}$, where $S$ is the speed in rpm. In general, the bearing loss can be described using two aspects of the deceleration data: the rate extrapolated to zero speed, and the slope of the rate versus speed. The zero intercept of the former provides an indication of hysteresis loss caused by circumferential inhomogeneities of the rotating permanent magnet interacting with the HTSs. This loss provides a constant angular deceleration at all speeds, but, more importantly, any heat generated by this loss must be removed at cryogenic temperature. The slope of the deceleration rate is an indication of eddy current losses in the system. Eddy losses contribute to the angular deceleration of the rotor, but any heat generated is removed at ambient temperature (note: there are no metallic conductors in the cryostat). A refrigeration penalty therefore applies only to the hysteresis losses. Eddy losses include the interaction of inhomogeneities of the rotating permanent magnets with any stationary electrical conductor in the system and interaction of magnetic inhomogeneities of the HTS array with electrically conducting parts of the rotating part of the bearing.

The steady decrease in the slope of the rate from $4 / 26 / 01$ to $7 / 30 / 01$ and again to $1 / 18 / 01$ may be attributed to removal of miscellaneous electrically conducting support structure from the vicinity of the HTS bearing. Comparing the 1/17/02 and $1 / 18 / 02$ data, operation at $71 \mathrm{~K}$ provides a lower zero intercept than does operation at $77 \mathrm{~K}$. This is consistent with the hysteresis loss of an HTS being inversely proportional to the critical current density and the critical current density of YBCO rising as temperature decreases.

Often, the slope of the loss rate is constant over most of the speed range of an HTS bearing. Such is not the case for the $1 / 17 / 02$ and 1/18/02 data. Here the slope decreases above $10,000 \mathrm{rpm}$. We attribute two causes for this behavior. First, the rotating magnet consists of segments, so that the HTS is subject to hysteresis loss at harmonic frequencies of the rotational frequency. Thus, at $200 \mathrm{~Hz}(12,000 \mathrm{rpm})$ some of the magnetic fluctuations affecting the HTSs occur at frequencies well in excess of $400 \mathrm{~Hz}$. Previous measurements have shown that hysteresis loss in melt-textured YBCO decrease as frequency increases above this value [10]. Even allowing for a slight increase in hysteresis loss above the resonance due to rotor imbalance, this effect can account for at most about a $2 \mathrm{rpm} / \mathrm{min}$ departure from the linear value. Second, the magnetization of the HTS array is not uniform within a YBCO tile, and this will cause eddy currents in the $\mathrm{NdFeB}$ permanent magnets and in the steel rings of the rotor part of the bearing. Because the steel has a much higher electrical conductivity than the $\mathrm{NdFeB}$, we expect most of the eddy current loss to show up in the steel.

The geometry of the bearing is sufficiently complex that quantitative calculations of the eddy current losses in the steel would be suspect. However, a qualitative understanding of the speed dependence may be found by examining low and high-speed approximations of magnets moving in close proximity to stationary steel sheets of thickness $\mathrm{T}$ [11]. The speed dependence is in terms of a normalized velocity $\beta=$ $\mathrm{v} / \mathrm{v}_{0}$, where $\mathrm{v}$ is the velocity of the moving magnet, $\mathrm{v}_{0}=$ $4 \pi /\left(\mu_{0} \sigma \lambda\right), \mu_{0}=4 \pi \times 10^{-7} \mathrm{~N} / \mathrm{A}^{2}$ is the permeability of vacuum, $\sigma$ is the electrical conductivity, and $\lambda$ is the wavelength of the dominant Fourier component of the 
magnetic field in the direction of travel. Another parameter is the relative magnetic permeability $\mu_{r}=\mu / \mu_{0}$. The results are given in terms of the drag force divided by the image force. The image force is the force between the magnet and its image located at a distance twice that of the magnet to the track.

The calculated results are shown in Fig. 8 for two limiting conditions - high and low speed. The low-speed limit is independent of $\mu_{r}$. The high-speed limit has a weak $\mu_{r}$ dependence. The steel rings are between two permanent magnets of opposite polarity, and we expect that $\mu_{r}$ will vary considerably throughout the ring but should be close to saturation in most locations. Therefore a $\mu_{r}$ of 2 or 3 is probably correct. The calculations are strictly valid only away from $\beta=1$, however, the trends suggest that there may be a drag peak at or just below $\beta=1$. We assume an electrical conductivity for steel of $2.5 \times 10^{6} \mathrm{mho} / \mathrm{m}$, and $\lambda=0.04 \mathrm{~m}$. The critical velocity is then $100 \mathrm{~m} / \mathrm{s}$, and $\beta=1$ corresponds to about $10,000 \mathrm{rpm}$ for our bearing. This argument shows that the expected velocity dependence of eddy currents in the bearing steel is consistent with the experimental results.

From the data of Fig. 7 and other low-speed bearing spins (omitted for clarity), we have attempted to isolate the hysteresis loss component and compare its magnitude as a function of temperature and working gap. At sufficiently low speeds, eddy current effects become negligible and the deceleration rate becomes nearly flat with speed. We verified this behavior with data taken typically at 50,100, 150,200, and $400 \mathrm{rpm}$. With the moment of inertia $I_{p}$ known we can then calculate the hysteresis loss on a watts/rpm basis to get a reasonable estimate of the cryogenic bearing loss at the design speed of a flywheel. The results, shown in Fig. 9, show a temperature dependence that is roughly in inverse proportion to the critical current density of the single-grain YBCO.

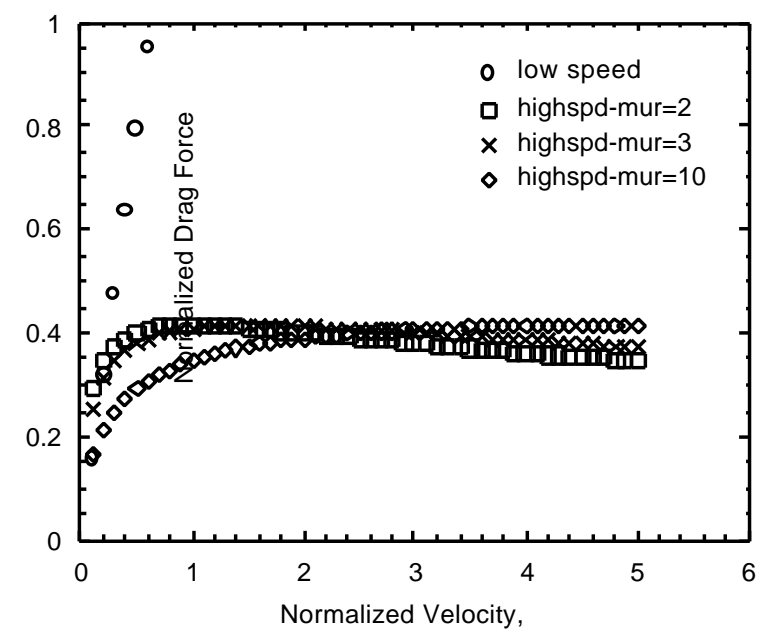

Fig. 8. Calculated low- and high-speed limits of normalized drag force in attractive levitation.

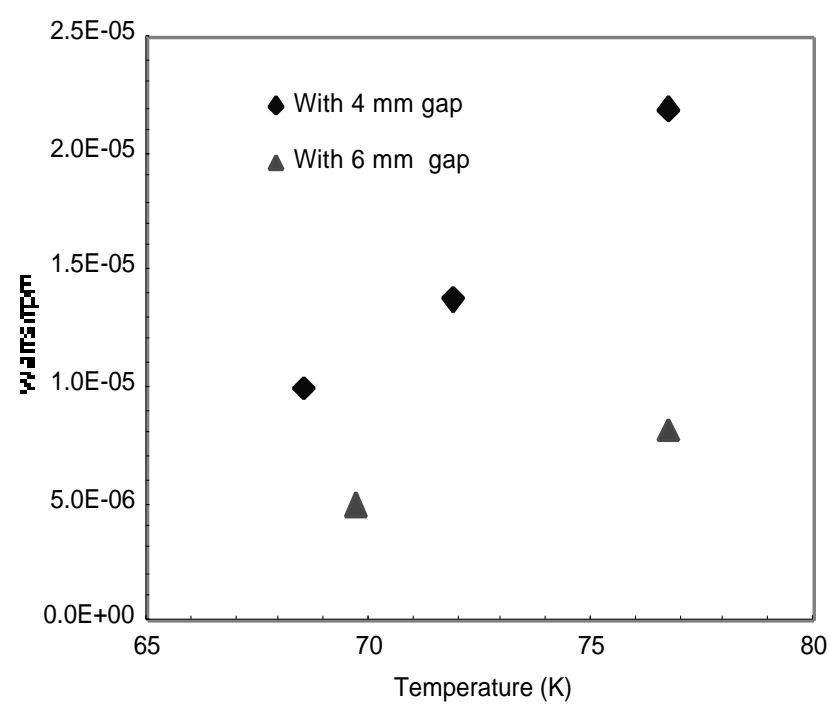

Fig. 9. Temperature dependence of hysteresis loss of bearing as derived from low-speed intercept of deceleration rate data.

\section{1-kWh Rotor Losses}

Rotational losses for the $1-\mathrm{kWh}$ rotor under several conditions are shown in Fig. 10. The deceleration rates in $\mathrm{rpm} / \mathrm{min}$ are smaller for this rotor than for the HTS bearing because the rotor has a much larger moment of inertia, about $1.06 \mathrm{~kg}-\mathrm{m}^{2}$.

The first series of tests was conducted with the motor/generator mounted on the rotor. During the 5-15-02 and 5-16-02 tests, the power electronics was still connected to the stator windings, and the voltage induced across the coils produced a small amount of loss in the "off" transistors. During the 5-30-02, 5-31-02, 6-06-02, and 6-09-02 tests, the coils were isolated from the electronics during idling. During the 6-18-02 tests, the motor/generator was removed and replaced by an aluminum disk so that the eddy current clutch could be used. For the 6-18-02 tests, two chamber pressures were used $-2 \times 10^{-3}$ torr, and $7 \times 10^{-5}$ torr. The data indicate that air drag was nearly negligible at the low pressure, as was confirmed by additional measurements at intermediate pressures. The low-pressure deceleration rates are thus due primarily to bearing drag.

Taking into account the increase in moment of inertia between the 1-kWh rotor and the test bearing, the important hysteretic loss component was nearly identical whether the bearing was used with the rotor or by itself. Eddy currents were proportionately larger on the $1-\mathrm{kWh}$ rotor, but increased vibration and an aluminum hub may account for the observed increase. These losses do not require cryogenic removal, and are reducible through better balancing of flywheel rotors and by minimizing conductive metals near the magnets. 


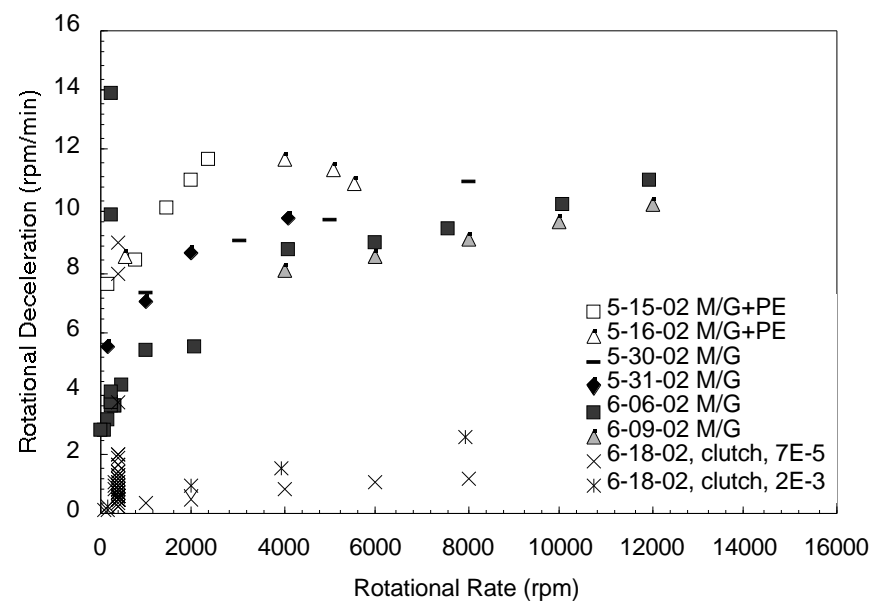

Fig. 10. Rotational loss vs. speed for the 1-kWh rotor.

The difference between the deceleration rates with the motor/generator attached or removed provides a direct estimate of the idling loss of the generator. Extrapolating the 6-06-02 and 6-09-02 data to zero speed, we can estimate the deceleration due to hysteresis loss in the back iron at $\sim 8 \mathrm{rpm} / \mathrm{min}$. Extrapolating the curves to an operating speed of 20,000 rpm, we get an additional $\sim 5 \mathrm{rpm} / \mathrm{min}$ deceleration from eddy currents in the coil and backiron. Assuming a generator-caused deceleration of $13 \mathrm{rpm} / \mathrm{min}$ and given the $1.06 \mathrm{~kg}-\mathrm{m}^{2}$ inertia, the generator idling loss at 20,000 rpm will be about 50 watts.

\section{DISCUSSION}

Data taken on deceleration of the test bearing showed strong temperature dependence only in the low-speed limit normally attributed to hysteresis loss in the superconductor (Fig. 9). Data taken as a function of speed (Fig. 7) showed that the spread between the $77 \mathrm{~K}$ and $71 \mathrm{~K}$ curves was nearly independent of speed, further strengthening the case that eddy currents in ambient-temperature conductors account for most of the observed loss.

Our target operating temperature for flywheel bearings is $70 \mathrm{~K}$. With a $4 \mathrm{~mm}$ working gap the hysteresis loss component should then contribute $1.1 \mathrm{~W} / \mathrm{rpm}$, or roughly $0.22 \mathrm{~W}$ at a speed of $20,000 \mathrm{rpm}$. Assuming an achievable refrigeration penalty of $30 \mathrm{~W}_{\mathrm{e}} / \mathrm{W}_{\mathrm{t}}$ this becomes $6.6 \mathrm{~W}_{\mathrm{e}}$ to a cooler. The eddy current loss in the current bearing will add $1.1 \mathrm{~W}$ for a net bearing loss of only $7.7 \mathrm{~W}$.

In practice, flywheel systems for commercial use will have to address and systematically reduce a number of other tare losses. The mechanical supports for the cryostat will introduce parasitic losses, as will transfer lines if required. As a first step we have measured such losses in our thermosyphon system using nitrogen boil off at various stages of assembly. In recent tests the cryostat support alone consumed over $12 \mathrm{~W}$, while other parts of the system brought the total cryogenic load to about $25 \mathrm{~W}$. A new cryostat support has been fabricated which should reduce the load by up to $10 \mathrm{~W}$. Ultimately the entire cryogenic load for a 10-kWh flywheel should be reducible to on the order of $5 \mathrm{~W}$.
As such reductions are achieved, the motor/generator and associated power electronics is likely to become the dominant tare losses in HTS-based flywheels. This may present opportunities for synergies with other superconducting technologies to combine in highly efficient energy storage devices of high specific power output.

\section{SUMMARY}

We have studied the temperature and speed characteristics of an HTS bearing suitable for many potential commercial applications. Deceleration rate data have been used to separate the loss mechanisms of eddy currents, air drag, and hysteresis. A non-linearity in the velocity dependence above $10,000 \mathrm{rpm}$ has been provisionally explained as arising from a drag peak. Tests of the bearing on a $1-\mathrm{kWh}$ flywheel showed it to have sufficient stiffness and stability throughout a wide speed range. When used in the $10-\mathrm{kWh}$ rotor, the HTS bearing loss, which includes the direct deceleration plus refrigeration power to run the bearing cooling, meets the project goal of being less than $0.1 \% / \mathrm{hr}$.

\section{REFERENCES}

[1] J. Hull, "Superconducting bearings," Supercond. Sci. Technol., vol. 13, pp. R1-R14, 2000.

[2] T. M. Mulcahy, J. R. Hull, K. L. Uherka, R. G. Abboud, and J. Juna, "Test results of 2-kWh flywheel using passive PM and HTS bearings," IEEE Trans. Appl. Supercond., vol. 11, pp. 1729-1734, June 2001.

[3] S. Nagaya, N. Kashima, M. Minami, H. Kawashima, and S. Unisuga, "Study on high-temperature superconducting magnetic bearing for 10 kWh flywheel energy storage system," IEEE Trans. Appl. Supercond., vol. 11, pp. 1649-1652, June 2001.

[4] T. M. Mulcahy, J. R. Hull, K. L. Uherka, R. C. Niemann, R. G. Abboud, J. P. Juna, and J. A. Lockwood, "Flywheel energy storage advances using HTS bearings," IEEE Trans. Appl. Supercond., vol. 9, pp. 297-300, June 1999.

[5] T. Coombs, A. M. Campbell, R. Storey, and R. Weller, "Superconducting magnetic bearings for energy storage flywheels," IEEE Trans. Appl. Supercond., vol. 9, pp. 968-971, June 1999.

[6] Y. Miyagawa, H. Kameno, R. Takahata, and H. Ueyama, "A $0.5 \mathrm{kWh}$ flywheel energy storage system using a high-Tc superconducting magnetic bearing," IEEE Trans. Appl. Supercond., vol. 9, pp. 996-999, June 1999.

[7] A. C. Day, M. Strasik, K. E. McCrary, P. E. Johnson, J. W. Gabrys, J. R. Schindler, R. A Hawkins, D. L. Carlson, M. D. Higgins, and J. R. Hull, "Design and testing of the HTS bearing for a $10 \mathrm{kWh}$ flywheel system," Supercond. Sci. Technol., vol. 15, pp. 838-841, 2002.

[8] T. M. Mulcahy, J. R. Hull, K. L. Uherka, R. C. Niemann, R. G. Abboud, J. P. Juna, and J. A. Lockwood, "Flywheel energy storage advances using HTS bearings," IEEE Trans. Appl. Supercond., vol. 9, pp. 297-300, June 1999.

[9] J. R. Hull and A. Cansiz, "Vertical and lateral forces between a permanent magnet and a high-temperature superconductor," J. Appl. Phys., vol. 86, pp. 6396-6404, 1999.

[10] Z. J. Yang and J. R. Hull, "Frequency dependence of ac-loss of melttextured Y123 superconductor," IEEE Trans. Appl. Supercond., vol. 7, pp. 318-321, June 1997.

[11] S. W. Lee and R. Menendez, "Forces at low- and high-speed limits in magnetic levitation systems," J. Appl. Phys., vol. 46, pp. 422-425, Jan. 1975. 